\title{
Solubility Evaluation of Different Root Canal Sealing Materials
}

\author{
${ }^{1}$ Emre Bayram, ${ }^{2}$ Dilek Dalat, ${ }^{3}$ Melike Bayram
}

\begin{abstract}
Aim: To evaluate the solubility of five different root canal sealers (AH Plus Jet, RealSeal SE, MTA Fillapex, Tubli-Seal, and Acroseal) in chloroform, eucalyptol and Endosolv-E solvents.

Materials and methods: Ninety root canal sealer samples were prepared and then divided into three groups for immersion in a solvent for 2, 5 or 10 minutes. The mean values of the root canal sealers' dissolution in the solvents were obtained by the difference between the preimmersion original weight and the post-immersion weight on a digital analytical scale. Data were statistically analyzed by a Kruskal-Wallis test with a Bonferroni correction.
\end{abstract}

Results: Chloroform was a more effective solvent than eucalyptol or Endosolv $E$ for all root canal sealers, except for RealSeal SE, at all time points $(p<0.003)$. RealSeal SE was the least soluble sealer in all solvents at all time points.

Conclusion: Chloroform demonstrated a superior ability over other solvents in dissolving canal sealing materials, and eucalyptol was found to be the least effective solvent in this study.

Clinical significance: This study can help to the clinicians about which solvent should be preferred for solving the filling materials in retreatment cases.

Keywords: Endodontic sealers, Retreatment, Solubility, Solvents.

How to cite this article: Bayram E, Dalat D, Bayram M. Solubility Evaluation of Different Root Canal Sealing Materials. J Contemp Dent Pract 2015;16(2):96-100.

Source of support: Nil

Conflict of interest: None declared

\section{INTRODUCTION}

A combination of gutta-percha and root canal sealers are commonly used in root canal filling materials. Guttapercha used without a root canal sealer is not adequate to completely fill the root canal system. ${ }^{1}$ A paste-type

1,3Department of Endodontics, Gaziosmanpasa University Tokat, Turkey

${ }^{2}$ Department of Endodontics, Ankara University, Ankara Turkey

Corresponding Author: Emre Bayram, Assistant Professor Department of Endodontics, Gaziosmanpasa University, Tokat Turkey, Phone: 03562300036, e-mail: bayremre@yahoo.com sealer is essential as both a binding agent and to fill irregularities; sealers cement the gutta-percha to the dentin and can be used to fill accessory canals, anastomoses and multiple foramina. ${ }^{2}$

Teeth may need to be retreated for a variety of reasons. In cases of inadequate cleaning or filling of the root canal system, procedural errors, or reinfection of the primary sealed root canal caused by coronal or apical leakage, retreatment is indicated. ${ }^{3-5}$ A large portion of the guttapercha and sealers should be removed in order to reach the bacteria and tissue residues that are the causes of endodontic failure.

To date, many published reports have illustrated that it is difficult to completely eliminate filling materials from the walls of the major canals during retreatment; it is presumably even more difficult to clean microscopic residues. ${ }^{6-8}$

Different methods are used to remove root canal filling materials. These methods include the heat method, hand tools, mechanical and ultrasonic instruments used in mechanical methods, ${ }_{1}^{10}$ laser irradiation, ${ }_{11}^{11}$ and chemicals. Chemical methods, either alone or in combination, are preferred for the removal of canal filling materials. ${ }^{12}$ Removal techniques are dependent upon canal size and anatomy, condensation degree, and quantity of guttapercha. ${ }^{8,13}$ Sealer used in conjunction with gutta-percha may remain inaccessible to mechanical removal when located in anatomical ramifications. ${ }^{14,15}$ In such cases, solvents are essential for a thorough cleaning of the filling material from the root canal system, debris removal, and to provide effective disinfection. ${ }^{15}$

The removal of gutta-percha by mechanical means can lead to unwanted outcomes such as root perforation and changing the original shape of the root canal. Therefore, the use of solvent greatly facilitates the removal of filling material. ${ }^{4}$ An ideal solvent for endodontic retreatment balances the requirements of an acceptable level of clinical safety, level of toxicity and tissue destruction, and chemical capacity for dissolution. ${ }^{16}$

The purpose of this in vitro study was to evaluate the solubility of five different root canal sealers (AH Plus, RealSeal SE, MTA Fillapex, Tubli-Seal and Acroseal) in different solvents (chloroform, eucalyptol and Endosolv E). 


\section{MATERIALS AND METHODS}

Epoxy resin-based AH Plus Jet (Dentsply De Trey, Konstanz, Germany), calcium hydroxide-based Acroseal (Septodont, Saint-Maur-des-Fosses Cedex, France), zinc oxide and eugenol-based Tubli-Seal (Kerr, USA), MTAbased MTA Fillapex (Angelus Industria de Produtos Odontologicos S/A, Londrina-PR. Brasil), and resinbased RealSeal SE (SybronEndo, Glendora, USA) were tested in this study.

Stainless steel ring molds with an internal diameter of $8 \mathrm{~mm}$ and a height of $2 \mathrm{~mm}$ were used to prepare 90 samples of root canal filling material. All sample molds were cleaned with acetone in an ultrasonic bath for 15 minutes and weighed in triplicate prior to use (AND GR - 202, Tokyo, Japan). All weight measurements throughout the study were in grams recorded to five decimal places. Molds were supported by a larger glass plate and covered with a cellophane sheet. Sealer cements were mixed in accordance with the manufacturer's instructions, and then freshly mixed materials were carefully flowed to excess into the sample molds, avoiding air entrapment. Another glass plate, also covered with cellophane film, was positioned on the mold and pressed manually in such a way that the plates were in contact with the entire mold in a uniform manner. The assembly was placed in an incubator $\left(37^{\circ} \mathrm{C}, 95 \%\right.$ relative humidity) and left to set for 24 hours. Excess material was then trimmed level with the surface of the mold with a sharp scalpel. Before the immersion of the samples, all sealers were weighed in their molds three times and the average value was recorded $\left(\mathrm{m}_{1}\right)$.

Ninety samples of each endodontic sealer were prepared and divided into three groups of 30 . The groups were further divided into three subgroups of 10 , according to the immersion period (2, 5 or 10 minutes). The selected solvents were eucalyptol (Dentsply, Trappes, France), chloroform (Aklar Kimya, Ankara, Turkey), and
Endosolv E (Septodont, Saint-Maur-des-Fosses Cedex, France).

At room temperature, sealer samples were immersed in $20 \mathrm{ml}$ of solvent. Both surfaces of the samples were accessible to the solvent. We removed the sealer samples from the solvents after the specified immersion period by using a pair of tweezers, touching only the metal mold. Then, the samples were washed with $100 \mathrm{ml}$ of doubledistilled water and then blotted dry with absorbent paper. Samples were allowed to dry in an oven for 24 hours at $37 \pm 1^{\circ} \mathrm{C}$ and then kept in a dehumidifier/desiccator. Thereafter, they were weighed $\left(\mathrm{m}_{2}\right)$, and the amount of sealer removed from the specimen was determined as the difference between the original weight of the sealer and its final weight. The weight loss of each sample, expressed as a percentage of the original mass, was considered the solubility of the tested material.

The differences in dissolution of root canal sealers for different durations and in different solvents were tested and calculated using Kruskal-Wallis tests with Bonferroni corrections $(p<0.003)$. Kruskal-Wallis tests with Bonferroni corrections were also further performed to compare the amount of dissolution of the root canal sealers, with the level of statistical significance set at $\mathrm{p}<0.006$.

\section{RESULTS}

Dissolution means and standard deviations are reported as percentages for the sealers immersed in different solvents and presented in (Table 1).

Chloroform was a more effective solvent than eucalyptol or Endosolv E for all root canal sealers, with the exception of RealSeal SE, at all time points $(\mathrm{p}<0.003$ (Graph 1).

\section{DISCUSSION}

In a study by Bodrumlu ${ }^{17}$ the solubilities of AH Plus, Epiphany, and Ketac-Endo sealers were tested in

Table 1: The mean percentage ( \pm standard deviation) of weight loss for each endodontic sealer in different solvents over time

\begin{tabular}{|c|c|c|c|c|c|c|c|c|c|}
\hline & \multicolumn{3}{|c|}{ Chloroform } & \multicolumn{3}{|c|}{ Eucalyptol } & \multicolumn{3}{|c|}{ Endosolv $E$} \\
\hline & $2 \mathrm{~min}$. & $5 \mathrm{~min}$. & $10 \mathrm{~min}$. & $2 \mathrm{~min}$. & $5 \mathrm{~min}$. & $10 \mathrm{~min}$. & $2 \mathrm{~min}$. & $5 \mathrm{~min}$. & $10 \mathrm{~min}$. \\
\hline AH Plus & $\begin{array}{l}27.53^{\mathrm{A}, \mathrm{a}} \\
( \pm 3.46)\end{array}$ & $\begin{array}{l}60.34)^{\mathrm{B}, \mathrm{a}} \\
( \pm 7.00)\end{array}$ & $\begin{array}{l}97.28^{\mathrm{C}, \mathrm{a}} \\
( \pm 2.65)\end{array}$ & $\begin{array}{l}0.73^{\mathrm{C}, \mathrm{bc}} \\
( \pm 0.44)\end{array}$ & $\begin{array}{l}1.58^{\mathrm{A}, \mathrm{ab}} \\
( \pm 0.59)\end{array}$ & $\begin{array}{l}2.79^{\mathrm{B}, \mathrm{a}} \\
( \pm 0.57)\end{array}$ & $\begin{array}{l}4.99^{\mathrm{B}, \mathrm{bc}} \\
( \pm 1.91)\end{array}$ & $\begin{array}{l}7.92^{\mathrm{C}, \mathrm{c}} \\
( \pm 1.91)\end{array}$ & $\begin{array}{l}13.22^{\mathrm{A}, \mathrm{abc}} \\
( \pm 2.27)\end{array}$ \\
\hline RealSeal & $\begin{array}{l}0.33^{A, d} \\
( \pm 0.20)\end{array}$ & $\begin{array}{l}0.62^{\mathrm{A}, \mathrm{d}} \\
( \pm 0.31)\end{array}$ & $\begin{array}{l}0.72^{A, e} \\
( \pm 0.31)\end{array}$ & $\begin{array}{l}0.34^{\mathrm{A}, \mathrm{cd}} \\
( \pm 0.09)\end{array}$ & $\begin{array}{l}0.35^{\mathrm{A}, \mathrm{C}} \\
( \pm 0.20)\end{array}$ & $\begin{array}{l}0.49^{A, C} \\
( \pm 0.32)\end{array}$ & $\begin{array}{l}0.34^{\mathrm{A}, \mathrm{d}} \\
( \pm 0.27)\end{array}$ & $\begin{array}{l}0.33^{A, d} \\
( \pm 0.26)\end{array}$ & $\begin{array}{l}0.56^{A, d} \\
( \pm 0.45)\end{array}$ \\
\hline MTA & $\begin{array}{l}7.53^{\mathrm{A}, \mathrm{cd}} \\
( \pm 1.56)\end{array}$ & $\begin{array}{l}11.03^{\mathrm{B}, \mathrm{cd}} \\
( \pm 3.44)\end{array}$ & $\begin{array}{l}17.38^{\mathrm{C}, \mathrm{de}} \\
( \pm 5.73)\end{array}$ & $\begin{array}{l}1.36^{\mathrm{C}, \mathrm{ab}} \\
( \pm 0.35)\end{array}$ & $\begin{array}{l}3.11^{\mathrm{A}, \mathrm{a}} \\
( \pm 1.14)\end{array}$ & $\begin{array}{l}3.15^{\mathrm{A}, \mathrm{a}} \\
( \pm 1.46)\end{array}$ & $\begin{array}{l}2.58^{\mathrm{D}, \mathrm{cd}} \\
( \pm 0.63)\end{array}$ & $\begin{array}{l}9.04^{\mathrm{B}, \mathrm{bc}} \\
( \pm 7.94)\end{array}$ & $\begin{array}{l}10.44^{\mathrm{B}, \mathrm{C}} \\
( \pm 7.85)\end{array}$ \\
\hline Tubli seal & $\begin{array}{l}19.23^{A, a b} \\
( \pm 3.64)\end{array}$ & $\begin{array}{l}31.54^{\mathrm{B}, \mathrm{ab}} \\
( \pm 4.12)\end{array}$ & $\begin{array}{l}41.65^{\mathrm{C}, \mathrm{c}} \\
( \pm 3.77)\end{array}$ & $\begin{array}{l}1.70^{\mathrm{D}, \mathrm{a}} \\
( \pm 0.82)\end{array}$ & $\begin{array}{l}2.07^{\mathrm{D}, \mathrm{a}} \\
( \pm 0.60)\end{array}$ & $\begin{array}{l}2.87^{\mathrm{A}, \mathrm{a}} \\
( \pm 0.56)\end{array}$ & $\begin{array}{l}11.06^{\mathrm{C}, \mathrm{a}} \\
( \pm 2.27)\end{array}$ & $\begin{array}{l}18.03^{A, a} \\
( \pm 1.70)\end{array}$ & $\begin{array}{l}27.66^{\mathrm{B}, \mathrm{a}} \\
( \pm 1.92)\end{array}$ \\
\hline Acroseal & $\begin{array}{l}14.36^{A, b c} \\
( \pm 0.66)\end{array}$ & $\begin{array}{l}30.10^{\mathrm{B}, \mathrm{bc}} \\
( \pm 1.85)\end{array}$ & $\begin{array}{l}41.69^{\mathrm{C}, \mathrm{bc}} \\
( \pm 2.20)\end{array}$ & $\begin{array}{l}0.12^{\mathrm{B}, \mathrm{d}} \\
( \pm 0.05)\end{array}$ & $\begin{array}{l}0.56^{\mathrm{D}, \mathrm{bc}} \\
( \pm 0.23)\end{array}$ & $\begin{array}{l}0.86^{\mathrm{D}, \mathrm{bc}} \\
( \pm 0.45)\end{array}$ & $\begin{array}{l}5.68^{\mathrm{C}, \mathrm{abc}} \\
( \pm 0.83)\end{array}$ & $\begin{array}{l}9.05^{\mathrm{A}, \mathrm{abc}} \\
( \pm 1.27)\end{array}$ & $\begin{array}{l}11.85^{\mathrm{B}, \mathrm{bc}} \\
( \pm 1.06)\end{array}$ \\
\hline
\end{tabular}

The means that are followed by the same superscript uppercase letter in the rows indicate no statistically significant difference among the solvents for each endodontic sealer $(p<0.003)$. In the columns, the same superscript lower-case letter indicates no statistically significant difference among the endodontic sealers for each solvent $(p<0.006)$ 


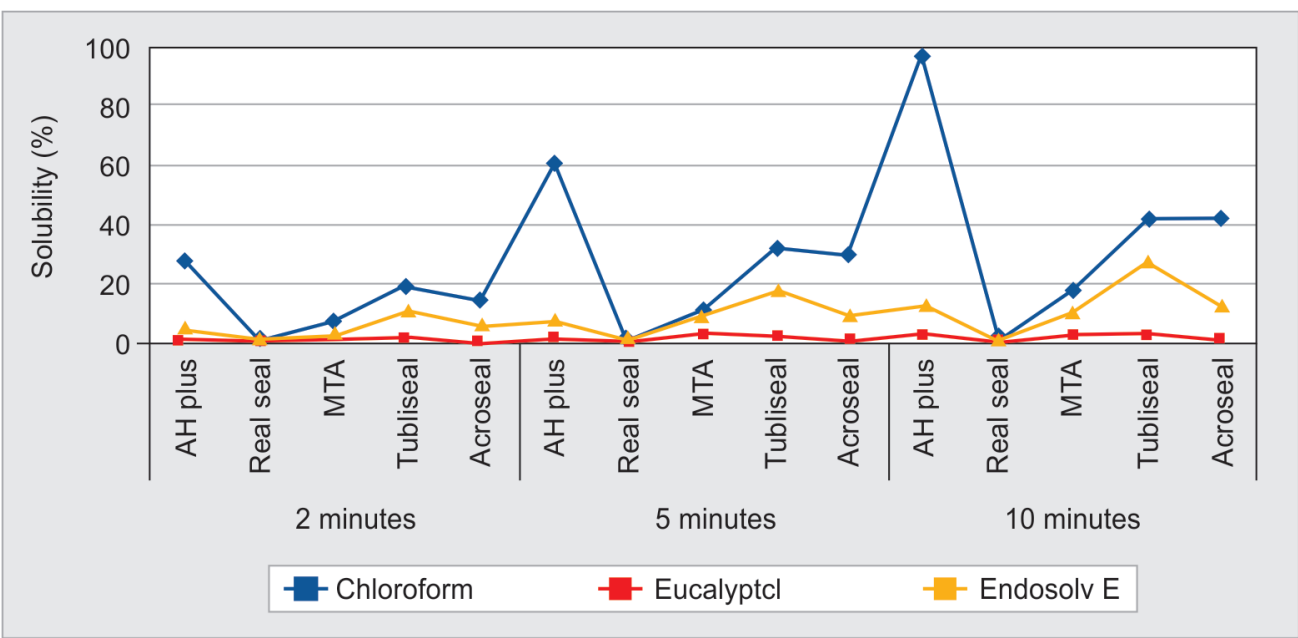

Graph 1: The mean percentage of weight loss for each endodontic sealer in different solvents over time

eucalyptus oil, chloroform, and distilled water as a control. It was found that there was no statistically significant difference between the root canal sealers at 2 or 5 minutes, and the epiphany root canal sealer showed statistically greater solubility than the $\mathrm{AH}$ Plus sealer at 10 minutes in the solvents.

Epiphany and Epiphany SE are dual-curable resin composites containing a redox catalyst. ${ }^{18}$ RealSeal SE and Epiphany SE have the same structure as fourthgeneration self-etching methacrylate resin-based root canal sealers. The manufacturer of epiphany states that 40 seconds of light is required to cure the coronal region of the sealer, whereas the entire filling will cure chemically in approximately 15 to 30 minutes.

In a study by Resende ${ }^{19}$ even though epiphany and epiphany SE were mixed and manipulated in a darkroom during the experiment, a thin, superficial, non-cured layer was always observed after the required setting time after the specimens were exposed to a curing light source. According to Franco, ${ }^{20}$ oxygen inhibited vinyl polymerization in composite resins, and 40 to $60 \%$ of the carbon bonds remained unsaturated. The lack of uniform photoactivation throughout the sample contributes to incomplete polymerization, leaving residual monomers in the sealer in the deepest recesses of the sample. ${ }^{21} \mathrm{Com}$ pared to the results of Bodrumlu, ${ }_{17}$ our results indicate that RealSeal SE was the least soluble root canal sealer in the solvents tested. This difference may be resulted from the insufficient polymerization of the epiphany sealer. Mathias-Junior, ${ }^{22}$ observed that the solubilities of lightactivated epiphany and uncured epiphany sealers were significantly different in distilled water. Photoactivation may cause an interlocking of the polymeric chains, creating a more rigid and closed structure and thus, hindering the mobility of $\mathrm{Ca}^{2+}$ ions inside the sealer matrix.

In our study, RealSeal SE showed less solubility than other root canal sealers. This result may be because
RealSeal SE has a more rigid structure after light activation. However, study by Martos, ${ }^{12}$ supported our results regarding RealSeal SE. They found that there was no significant difference in weight at 2, 5 or 10 minutes for RealSeal SE in chloroform or eucalyptus oil.

Chloroform was a more effective solvent than eucalyptol for the MTA Fillapex root canal sealer. However, MTA Fillapex dissolved more than other root canal sealers in eucalyptol. There are few published reports on retreatment efficiency following the use of this material, or on the actions of other solvents. In spite of this, there are no reports of MTA Fillapex solubility in different organic solvents. ${ }^{23,24}$ In our findings, MTA Fillapex had the greatest solubility in chloroform at 2,5 and 10 minutes. In addition, eucalyptol was found to be the least effective solvent for this root canal sealer.

In several previous studies, AH Plus demonstrated greater solubility than calcium hydroxide-based sealers or a zinc oxide and eugenol-based sealers in chloroform solvent. ${ }^{25}$ In the present study, almost all of the AH Plus had dissolved at 10 minutes, and the solubility of AH Plus was higher than that of Acroseal or Tubli-Seal root canal sealer in chloroform. Our results were similar to those of Whitworth ${ }^{25}$ and Schafer. ${ }^{26}$ Schafer ${ }^{26}$ observed that AH Plus was less soluble than $\mathrm{Ca}(\mathrm{OH})_{2}$ and eugenol-based sealers in eucalyptus oil that contained $85 \%$ eucalyptol.

Tanomaru-Filho ${ }^{27}$ showed that the solvent action of eucalyptol was effective on eugenol-based sealers, but no action was found on the resin-based sealers AH Plus, Epiphany, or EndoREZ, or on the silicone-based sealer Roekoseal. These findings support the results of our study. According to our results, Tubli-Seal was significantly more soluble than Acroseal, but the difference was not significant between AH Plus and Tubli-Seal at 5 or 10 minutes in the eucalyptol solvent group.

Tetrachloroethylene is the main compound in Endosolv E, which has been used to dissolve zinc oxide and 
eugenol sealers. ${ }^{28}$ This study showed that the solubility of Tubli-Seal was higher than that of other root canal sealers in Endosolv $\mathrm{E}$ at all time points.

A reduction in solubility and the disintegration of zinc oxide and eugenol-based ( $\mathrm{ZnOE}$ ) cements when natural resin was added to the composition. ${ }^{29}$ However, Martos ${ }^{30}$ observed that most $\mathrm{ZnOE}$-based filling cements have vegetable resin in their compositions; they are composed of approximately $90 \%$ resinous acids and are soluble in solvents commonly used for endodontic retreatment.

In previous studies, researchers have reported that calcium hydroxide-based sealers showed a low level of solubility in solvents. The solubility of Acroseal was less than that of the Tubli-Seal root canal sealer in eucalyptol. This may result from the relative insolubility of its ingredients; it contains bisphenol A diglycidyl ether and methenamine, which are epoxy compounds found in the structures of AH 26 and Sealer 26. 25,30

\section{CONCLUSION}

Chloroform displayed a superior ability in dissolving canal sealing materials over the other solvents tested, and the least solvent capacity was obtained with eucalyptol. AH Plus was the most soluble sealer in chloroform solvent and almost all of the AH Plus had dissolved in chloroform at 10 minutes. RealSeal SE was the least soluble sealer in all solvents and at all time points. The solubility of all canal filling sealers, with the exception of RealSeal SE, significantly increased with increasing time.

\section{ACKNOWLEDGMENT}

This study was supported by the Unit of the Scientific Research Projects of Ankara University Faculty of Dentistry in 2011.

\section{REFERENCES}

1. H Bhandi S, T SS. Comparative evaluation of sealing ability of three newer root canal obturating materials guttaflow, resilon and thermafil: an in vitro study. J Int Oral Health 2013;5(1):54-65.

2. Gilhooly RM, Hayes SJ, Bryant ST, Dummer PM. Comparison of cold lateral condensation and a warm multiphase gutta-percha technique for obturating curved root canals. Int Endod J 2000;33(5):415-420.

3. Saunders WP, Saunders EM. Coronal leakage as a cause of failure in root-canal therapy: a review. Endod Dent Traumatol 1994;10(3):105-108.

4. Wourms DJ, Campbell AD, Hicks ML, Pelleu GB Jr. Alternative solvents to chloroform for gutta-percha removal. J Endod 1990;16(5):224-226.

5. Uemura M, Hata G, Toda T, Weine FS. Effectiveness of eucalyptol and d-limonene as gutta-percha solvents. J Endod 1997;23(12):739-741.
6. Zuolo ML, Imura N, Ferreira MO. Endodontic retreatment of thermafil or lateral condensation obturations in post space prepared teeth. J Endod 1994;20(1):9-12.

7. Moshonov J, Trope M, Friedman S. Retreatment efficacy 3 months after obturation using glassionomercement, zinc oxideeugenol, and epoxy resin sealers. J Endod 1994;20(2):90-92.

8. Ladley RW, Campbell AD, Hicks ML, Li SH. Effectiveness of halothane used with ultrasonic or hand instrumentation to remove gutta-percha from the root canal. J Endod 1991; 17(5):221-224.

9. Ezzie E, Fleury A, Solomon E, Spears R, He J. Efficacy of retreatment techniques for a resin-based root canal obturation material. J Endod 2006;32(4):341-344.

10. RingJ,Murray PE, Namerow KN, Moldauer BI, Garcia-Godoy F. Removing root canal obturation materials: a comparison of rotary file systems and re-treatment agents. J Am Dent Assoc 2009;140(6):680-688.

11. Tachinami H, Katsuumi I. Removal of root canal filling materials using Er:YAG laser irradiation. Dent Mater J 2010; 29(3):246-252.

12. Martos J, Bassotto AP, Gonzalez-Rodriguez MP, Ferrer-Luque CM. Dissolving efficacy of eucalyptus and orange oil, xylol and chloroform solvents on different root canal sealers. Int Endod J 2011;44(11):1024-1028.

13. Mounce R. Current concepts in gutta-percha removal in endodontic retreatment. N Y State Dent J 2004;70(7):32-35.

14. Friedman S, Moshonov J, Trope M. Efficacy of removing glass ionomer cement, zinc oxide eugenol, and epoxy resin sealers from retreated root canals. Oral Surg Oral Med Oral Pathol 1992;73(5):609-612.

15. Zaccaro Scelza MF, Lima Oliveira LR, Carvalho FB, CorteReal Faria S. In vitro evaluation of macrophage viability after incubation in orange oil, eucalyptol, and chloroform. Oral Surg Oral Med Oral Pathol Oral Radiol Endod 2006; 102(3):e24-27.

16. Magalhaes BS, Johann JE, Lund RG, Martos J, Del Pino FA. Dissolving efficacy of some organic solvents on gutta-percha. Braz Oral Res 2007;21(4):303-307.

17. Bodrumlu E, Er O, Kayaoglu G. Solubility of root canal sealers with different organic solvents. Oral Surg Oral Med Oral Pathol Oral Radiol Endod 2008;106(3):e67-69.

18. Pawinska M, Kierklo A, Marczuk-Kolada G. New technology in endodontics-the Resilon-Epiphany system for obturation of root canals. Adv Med Sci 2006;51 Suppl 1:154-157.

19. Resende LM, Rached-Junior FJ, Versiani MA, et al. A comparative study of physicochemical properties of AH Plus, Epiphany, and Epiphany SE root canal sealers. Int Endod J 2009;42(9):785-793.

20. Franco EB, Lopes LG, D'Alpino PH, et al. Evaluation of compatibility between different types of adhesives and dualcured resin cement. J Adhes Dent 2002;4(4):271-275.

21. Rached-Junior FJ, Souza-Gabriel AE, Alfredo E, et al. Bond strength of Epiphany sealer prepared with resinous solvent. J Endod 2009;35(2):251-255.

22. Mathias-Junior O, Souza-Gabriel AE, Saraiva Miranda CE, etal. Solubility of Epiphany endodontic sealer prepared with resinous solvent. J Endod 2009;35(5):715-718.

23. Neelakantan P, Grotra D, Sharma S. Retreatability of 2 mineral trioxide aggregate-based root canal sealers: a cone-beam computed tomography analysis. J Endod 2013;39(7):893-896.

24. Carpenter MT, Sidow SJ, Lindsey KW, Chuang A, McPherson JC, 3rd. Regaining apical patency after obturation with gutta- 
percha and a sealer containing mineral trioxide aggregate. J Endod 2014;40(4):588-590.

25. Whitworth JM, Boursin EM. Dissolution of root canal sealer cements in volatile solvents. Int Endod J 2000;33(1):19-24.

26. Schafer E, Zandbiglari T. A comparison of the effectiveness of chloroform and eucalyptus oil in dissolving root canal sealers. Oral Surg Oral Med Oral Pathol Oral Radiol Endod 2002;93(5):611-616.

27. Tanomaru-Filho M, Orlando T, Bortoluzzi EA, Silva GF, Tanomaru JM. Solvent capacity of different substances on gutta-percha and Resilon. Braz Dent J 2010;21(1):46-49.
28. Faria-Junior NB, Loiola LE, Guerreiro-Tanomaru JM, Berbert FL, Tanomaru-Filho M. Effectiveness of three solvents and two associations of solvents on gutta-percha and resilon. Braz Dent J 2011;22(1):41-44.

29. Carvalho-Junior JR, Guimaraes LF, Correr-Sobrinho L, Pecora JD, Sousa-Neto MD. Evaluation of solubility, disintegration, and dimensional alterations of a glass ionomer root canal sealer. Braz Dent J 2003;14(2):114-118.

30. Martos J, Gastal MT, Sommer L, et al. Dissolving efficacy of organic solvents on root canal sealers. Clin Oral Investig 2006;10(1):50-54. 